\title{
Peripheral Target Choice by Homologous Neurons During Embryogenesis of the Medicinal Leech. II. Innervation of Ectopic Reproductive Tissue by Nonreproductive Retzius Cells
}

\author{
Curtis M. Loer" and William B. Kristan, Jr. \\ Department of Biology, University of California, San Dicgo, La Jolla, California 92093
}

\begin{abstract}
Most Retzius $(\mathbf{R z})$ cells innervate the body wall of their own and adjacent segments, whereas $\mathrm{Rz}$ cells in segments 5 and $6[\operatorname{Rz}(5,6)]$ innervate the reproductive tissue, which is found only in those segments. Results from the preceding paper (Loer and Kristan, 1989a) showed that $R z(5,6)$ and standard Rz cells do not normally compete for their respective peripheral targets. These experiments did not, however, distinguish between 2 other possible mechanisms of target selection: intrinsic differences in target preference or differences in the timing of target contact. In order to separate these possibilities experimentally, we transplanted reproductive primordia to standard segments. We found that standard Rz cells were capable of densely innervating ectopic reproductive tissue, provided the target was transplanted at an appropriate time and location. Furthermore, after some processes of standard Rz cells contacted ectopic reproductive tissue, the rest of the cell's processes slowed their growth in a way reminiscent of $R z(5,6)$ processes. These results strongly suggest that $R z(5,6)$ innervate reproductive tissue at least partly because their processes contact this target during a period that is optimal for them to associate with the target, or when the reproductive tissue is most attractive to $\mathrm{Rz}$ processes, or both.
\end{abstract}

In the preceding paper (Loer and Kristan, 1989a), we showed that standard Retzius $(\mathrm{Rz})$ cells and $\mathrm{Rz}(5,6)$ express strong preferences for their normal targets: standard $\mathrm{Rz}$ cells for body wall and $\mathrm{Rz}(5,6)$ for reproductive tissue. Standard $\mathrm{Rz}$ cells, at least those in ganglia 4 and7, do not innervate reproductive tissue, even in the absence of competition from $\mathrm{Rz}(5,6)$; likewise, $\mathrm{Rz}(5,6)$ innervate only reproductive tissue even if the local body wall remains totally uninnervated by other Rz cells. $\mathrm{Rz}(5,6)$ will innervate body wall only if the reproductive tissue is removed early in development. Thus, competition between $\mathrm{Rz}$ cells cannot explain the differences in the targets these cells normally choose. Two other possible explanations of our results

\footnotetext{
Received Apr. 12, 1988; revised July 15, 1988; accepted July 18, 1988.

We wish to thank John Jellies for invaluable advice and cooperation, Shirley Reynolds and Sheri Furgal for excellent technical support, and Carey Booth and Susan Sacks for help with statistical analyses. We also wish to thank John Jellies, Kathy French, and David Bentley for helpful comments on the manuscript. This work was supported by NIH Predoctoral Traineeship GM07313 to C.M.L. and NIH Research Grant NS20746 and a March of Dimes Research Grant to W.B.K.

Correspondence should be addressed to William B. Kristan, Department of Biology, B-022, University of California, San Diego, La Jolla, CA 92093.

${ }^{a}$ Present address: Department of Biochemistry and Biophysics, Box 0554, University of California, San Francisco, CA 94143.

Copyright (C) 1989 Society for Neuroscience $0270-6474 / 89 / 020528-11 \$ 02.00 / 0$
}

are (1) $\mathrm{Rz}(4,7)$, and by extension, all standard $\mathrm{Rz}$. cells, have an intrinsically lower affinity for reproductive tissue than do $\mathrm{Rz}$ $(5,6)$; or $(2) \mathrm{R}$ (4,7) have an aflinity similar to that of $\mathrm{Rz}(5,6)$ but do not contact reproductive tissue at an appropriate time during development. In normal development, of course, most standard Rz cells are never given the choice between reproductive tissue and body wall, because they are distant from segments 5 and 6.

In this paper, we will argue that the timing of contact and the availability of the target are probably more important in target selection by $\mathrm{Rz}$ cells than are intrinsic segmental differences in the neurons. We found that standard $\mathrm{Rz}$ cells were capable of densely innervating reproductive tissue, provided that the target was presented at an appropriate time and location. Furthermore, after some processes of standard $\mathrm{Rz}$ cells contacted ectopic reproductive tissue, the rest of the cell's processes slowed their growth in a way reminiscent of $\mathrm{Rz}(5,6)$ processes. These results indicate that, although there may be some intrinsic differences between segmentally homologous $\mathrm{Rz}$ cells, standard $\mathrm{Rz}$ cells, like $\mathrm{Rz}(5,6)$ (Loer et al., 1987), are strongly influenced by the targets they contact during embryogenesis. Preliminary accounts of some of these results have been reported earlier (Loer et al., 1985; Loer and Kristan, 1987).

\section{Materials and Methods}

Animals. Embryos of Hirudo medicinalis were obtained from a laboratory breeding colony, as previously described (Jellies et al., 1987; Loer 1988 ), and staged in days of development from the time of cocoon deposition at $22-23^{\circ} \mathrm{C}$ (Fernandez and Stent, 1982).

Transplantations. Embryos were anesthetized in cold $8 \%$ ethanol in leech saline and placed ventral side up in rectangular chambers cut into Sylgard-filled plastic petri plates. The embryos were restrained with 2 thin, flat plastic strips pinned down on either side across the germinal plate, effectively strapping the embryo in place but allowing access to the operation sites. Two embryos were placed in adjacent chambers, one to serve as donor, the other as host. A typical transplant consisted of a rectangular piece of germinal plate (body wall) from the ventral midline region spanning roughly 2 segments (Fig. 1). To free the tissue from the donor embryo, 2 lateral cuts followed by 2 longitudinal cuts were made with fine scissors. Next, the host transplant site was prepared by making a shallow cut $2-3$ segments in length on the ventral midline of the host. The tissue on either side of the cut pulled away slightly, leaving a gap along the midline of the germinal plate. Ganglia and major nerves were untouched during this procedure. The loosened tissue was removed from the donor and pressed into the host site. Tissue not placed into the site within 3-4 min after removal from the donor usually failed to integrate successfully into the host. Another plastic strip was strapped over the transplanted tissue for 15-20 min, after which the host embryo was returned to spring water. Approximately $90 \%$ of embryos survived the operations except in cocoons with generally ill health, when as many unopcratcd controls as cxperimental animals died.

Reproductive tissue was transplanted from one embryo to a non- 
The Journal of Neuroscience, February 1989, 9(2) 529



Figure 1. Illustration of the transplantation technique. A block of germinal plate containing reproductive primordia (dotted outlines in the tissue being transplanted) was removed from a donor and placed into a ventral midline slit in the body wall of the host. In this example, the donor tissue (from segments 5 and 6) contained both male and female reproductive primordia and was inserted into segments 10 and 11 of the host. Segments were numbered at this stage by counting from segment 2 , the most anterior segment containing nephridiopores (shown here as circles on either side of the ganglion). In this and all subsequent figures, anterior is up. The ganglia (also outlined by dots) are about $80-100 \mu \mathrm{m}$ across at this stage.

reproductive segment in another, and the reproductive tissue of the host was not perturbed in any way. For each transplantation experiment, we used embryos from a single cocoon from mid-day 9 to late day 10 of development. All transplantation was thus technically isochronic; that is, tissue was taken from hosts of the same age as the donor. However, because development proceeds from anterior to posterior, there was some difference in the state of maturation of donor and host segments. At the beginning of each experiment, 2 embryos from the cocoon were dissected, fixed, and subsequently stained with 5-HT anti-serum and an HRP-conjugated $2^{\circ}$ antibody (Jellies et al., 1987) to assess the developmental age of $\mathrm{Rz}$ cells at the time of the opcration.

Donor tissue came from segments 4 and 5 , containing male reproductive tissue alone; from segments 5 and 6 , containing both male and female reproductive tissue; from segments 6 and 7 , containing female reproductive tissue alone; or from segments 8 and 9 , which contained no reproductive tissue. Host transplant sites included some in segments 2-3 (anterior to the reproductive segments), but most were in segments 9-13 (posterior to and hence younger than the reproductive segments). Despite the anterior-posterior gradient of development, there were no obvious differences in the results of transplanting into different segments. The embryos fell into 3 categories: experimental hosts, which received transplants of reproductive tissue; control hosts, which received transplants of body wall; and unoperated controls. Following the manipulations. all embryos were placed individually in sterile $35 \times 10 \mathrm{~mm}$ plastic petri dishes in $5 \mathrm{ml}$ of sterile spring water (Jellies et al., 1987) and allowed to develop further. They were dissected $12 \mathrm{hr}$ to 7 days later and prepared for either 5-HT immunocytochemistry or for intracellular injection of individual cells with HRP.

Measurement of distance from ganglion to ectopic reproductive tissue. We measured the distance from the center of the ectopic reproductive tissue to the center of the nearest ganglion using an ocular micrometer and normalized it to the average length of a midbody segment. The segment length was measured between the nephridiopores, which are obvious segmental landmarks (see Fig. 1). The normalized distance was defined as the distance between the reproductive tissue and the ganglion divided by the average intersegmental distance. Thus, the maximum normalized distance for an ectopic reproductive pore on the ventral midline would be 0.50 , or halfway between 2 ganglia. Most ectopic reproductive tissue was centered on or very close to the ventral midline, so that the major component of its distance from a ganglion was longitudinal.

Staining of $R z$ cell peripheral processes. Staining with 5-HT antiserum and filling $\mathrm{Rz}$ cells with HRP were performed as previously described (Jellies et al., 1987; Loer and Kristan, 1989a)

Measurment of $R z$ cell peripheral processes. The lateral growth of $\mathrm{Rz}$ cell processes in 3 peripheral nerves (A, PP, DP) was measured as described in the preceding paper (Loer and Kristan, 1989a) at 2 and 4 d after transplantation. To compare the extent of serotonergic innervation in segments containing transplanted reproductive tissue with other segments, we defined 3 groups of experimental and control segments:

1. Reproductive tissue transplant segments $(\mathrm{T})$ : segments in experi- 
Figure 2. Segments $12-13$ in a $16 \mathrm{~d}$ embryo that received a transplant containing reproductive tissue. The preparation was dissected and stained with gold chloride to enhance contrast $(\mathrm{Hu}-$ mason, 1979). The structure of the ectopic reproductive tissue, although incomplete, is typical of normal reproductive tissue: One tapering lateral duct (epididymus and vas deferens, $V D$ ) extends posteriorly from the body of the male reproductive tissue, whereas one of the female oviducts ends abruptly in a spherical ovary $(O)$. The female reproductive tissue is somewhat obscured by ganglion 13 which lies dorsal to it.

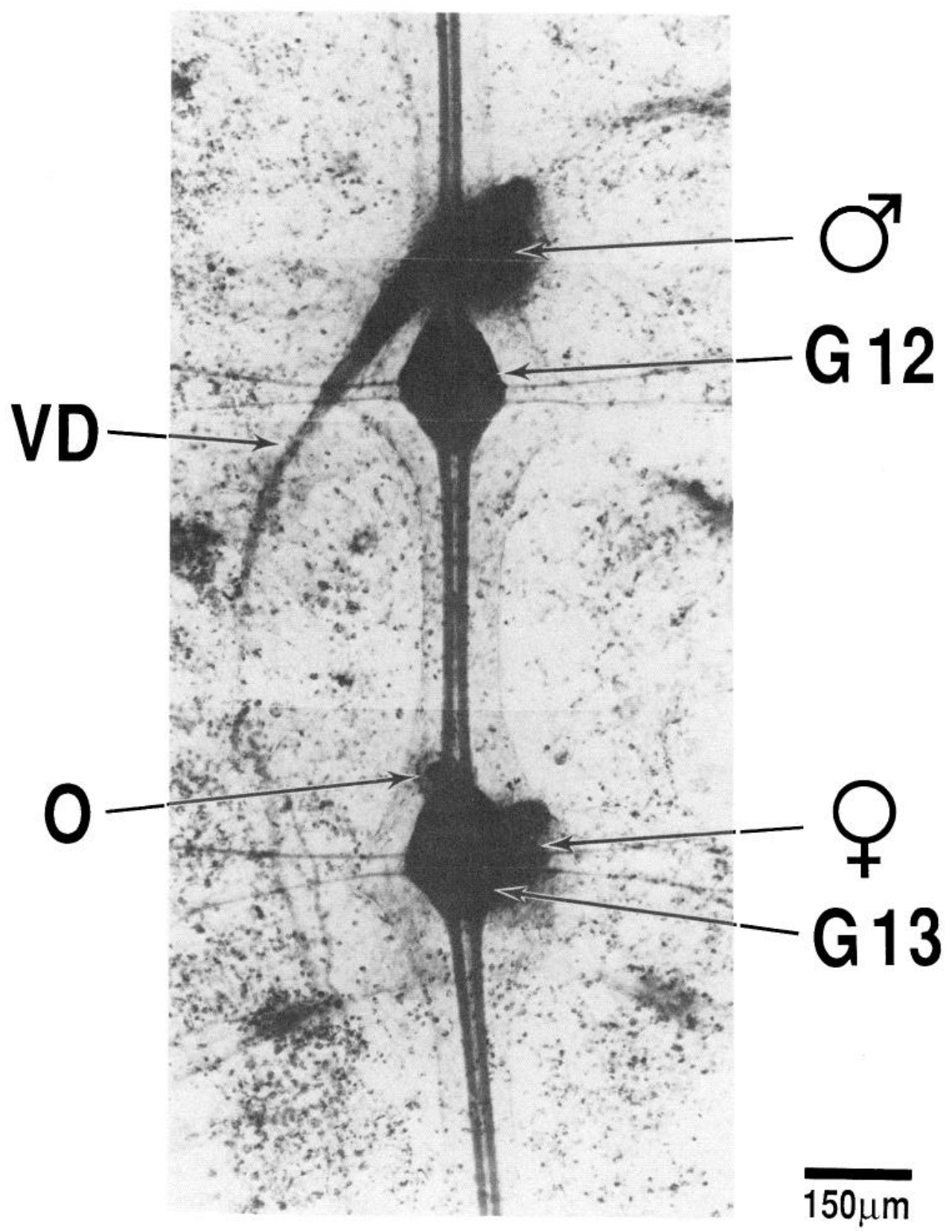

mental embryos in which ectopic male reproductive tissue was nearest to the ganglion. In the single case in which the ectopic gonopore was halfway between 2 ganglia, both segments were included in this category.

2. Body wall transplant (control) segments (TC): those segments in both experimental and operated control embryos that contained transplanted body wall but no reproductive tissue.

3. Unoperated segments (US): segments from experimental and operated control embryos that were 1 and 2 segments anterior or posterior to reproductive tissue transplant and body wall transplant segments; also, segments 9-13 from unoperated control embryos.

The lengths of processes on both sides of each segment were measured, except in a few cases in which one hemisegment was damaged during dissection.

Statistics. Most statistics were computed on an Apple Macintosh Plus computer using StatView 512+ (BrainPower, Inc.). Measurements of the distance from the ectopic pore to the ganglion were assigned to 1 of 3 groups according to the density with which the ectopic reproductive tissue was innervated (heavy, moderate, and light) and compared with ANOVA. Planned pairwise comparisons were made with additional $F$ tests (Sokal and Rohlf, 1981).
In the experiment that examined how ectopic reproductive tissue affected process outgrowth into the body wall, we tested for independence of measurements from the same segment before further statistical analysis. Only 5 of 24 groups showed significant correlation $(p<0.05)$ between measurements from the right and left sides, so the measurements from the 2 sides of each segment were treated as independent for further analysis.

Overall differences among the 3 groups of segments (T, TC, and US) for each set of measurements ( 2 and $4 \mathrm{~d}$ after transplantation for A, PP, and DP) were tested by ANOVA and pairwise comparisons made with Scheffe's $F$ test. Since the use of ANOVA could be inappropriate for comparisons in which the variances among the 3 groups were significantly different from one another or in which values were not distributed normally (Sokal and Rohlf, 1981), nonparametric analyses were also performed on these data. We used the Kruskal-Wallis test, sometimes called an analysis of variance by ranks (Kruskal and Wallis, 1952; from Zar, 1984), a test for which no assumptions of homoscedasticity or normality are necessary. Nonparametric pairwise comparisons were made using the method of Dunn (1964; from Zar, 1984). In spite of their lesser power, the results of nonparametric analyses were essentially the 

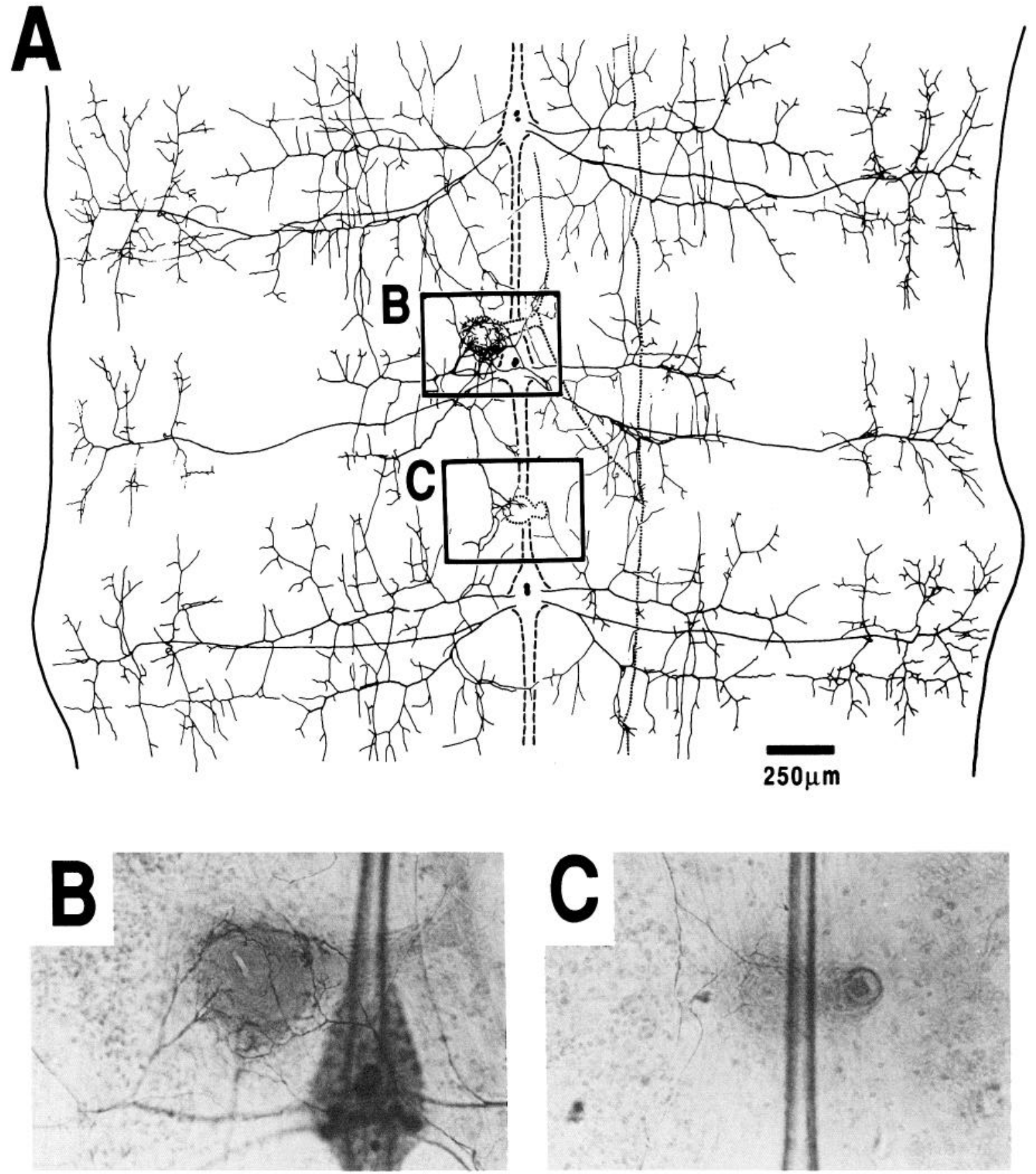

Figure 3. 5-HT innervation of ectopic reproductive tissue and body wall in a $16 \mathrm{~d}$ embryo. A, Camera lucida drawing of segments $9-11$ in a preparation stained with 5 -HT antiserum and HRP-conjugated $2^{\circ}$ antibody (anti-5-HT). For clarity, 5-HT-containing fibers and somata in the CNS are not drawn except for the outlines of the $\mathrm{Rz}$ cell bodies. Dashed lines indicate edges of ganglia and connectives of the CNS. The dotted outline indicates ectopic reproductive tissue, which lies ventral to the nerve cord. The vertical dotted line at right is the right vas deferens of the host embryo, which is joined by one duct from the ectopic reproductive tissue. The dark solid vertical lines on either side indicate the edges of the germinal plate. The extent of the photographs in $B$ and $C$ is indicated by the boxes. $B$, Photograph of ectopic male reproductive tissue from the preparation drawn in $A$. The innervation is as dense as seen in normal male reproductive tissue at this age. $C$, Photograph of ectopic female reproductive tissue from the preparation drawn in $A$. The density of innervation is much less than seen in normal female reproductive tissue, although it is slightly more dense than the innervation of the body wall. This pore was among the more densely innervated of transplanted female reproductive tissue.

same as the results of the ANOVA (i.e., although $p$ values were not identical, all comparisons showed the same significant differences in the nonparametric as in the parametric tests.

\section{Results}

Successfully transplanted reproductive primordia could be easily recognized in host embryos by the distinctive morphology of the organized reproductive tissue structures: dense, roughly spherical bodies with protruding ducts (Fig. 2). Of 121 surviving embryos that were dissected 2-7 d after reproductive tissue transplantation, 97 had recognizable reproductive structures incorporated into the host. Furthermore, large genital pores (gonopores) were usually visible on the ventral external surface in the transplant site. Ectopic male reproductive tissue was easily dis- 
Table 1. Innervation of ectopic male reproductive tissue as a function of age at transplantation

\begin{tabular}{lllll} 
Innervation & \multicolumn{5}{l}{ Age at transplantation } \\
\cline { 2 - 5 } density & $9_{\mathrm{m}}-9_{\mathrm{l}}$ & $9_{\mathrm{1}}-10_{\mathrm{e}}$ & $10_{\mathrm{c}}-10_{\mathrm{m}}$ & $10_{\mathrm{m} 1}-10_{1}$ \\
\hline Heavy & 9 & 2 & 0 & 0 \\
Moderate & 4 & 7 & 4 & 3 \\
Light & 4 & 4 & 1 & 4
\end{tabular}

The embryos were dissected 3-6 d after transplantation and stained with 5-HT antiserum and HRP-conjugated $2^{\circ}$ antibody. Subscripts refer to early (e), mid (m), or late (l) developmental days 9 and 10 .

tinguished from female by the distinctive appearance of the ducts leading into the central pore region: the male epididymus and vas deferens had an obvious lumen, and when a sufficiently long duct was present, it could be seen to taper gradually; the short female oviducts, on the other hand, ended in spherical ovaries. (Normal male and female reproductive structures at these stages are shown in Fig. 9 of the previous paper, Loer and Kristan, 1989a.) The full extent of transplanted body wall tissue was not so obvious, but it could often be distinguished by the modified pattern of body wall muscle and by the presence of ectopic nephridial tissue.

Initial observations of host embryos labeled with 5-HT antiserum showed that ectopic reproductive tissue was sometimes heavily innervated by serotonergic processes (Fig. 3). Many robust processes branched profusely about the central pore region of the tissue, often following novel pathways from the segmental nerves and forming additional nerves reminiscent of the "sex nerves" normally found only in segments 5 and 6 (Zipser, 1979; Jellies and Kristan, 1988). Ectopic reproductive tissue, however, was not always heavily innervated. For comparison, we divided embryos into 3 categories, based on the innervation of ectopic reproductive tissue: heavy - dense innervation by numerous robust, complex branches, very similar to that present in normal reproductive tissue; moderate-innervation not as substantial as that of normal reproductive tissuc, but clcarly more and/or heavier branches than normally present in an equivalent region of body wall; light/none-no serotonergic processes or no more than present normally in the body wall.

Ectopic male reproductive tissue was consistently more heavily innervated than female reproductive tissue. Ectopic female gonopores were heavily innervated in only 1 of 24 embryos assessed 3-6 d after transplantion; only 4 of 24 exhibited a moderate level of innervation. Ectopic male gonopores, on the other hand, were heavily innervated in 11 of 42 embryos and moderately innervated in 18 of 42 . Because of the higher success rate with transplanted male reproductive tissue, we used these transplants for all experiments to follow. The host transplant site (i.e., into segments 2-3 or 9-13) apparently had no effect on how successfully ectopic reproductive tissue was innervated by 5 -HT-containing processes.

\section{Factors influencing the innervation of ectopic reproductive tissue}

The age of the embryos at the time that male reproductive tissue was transplanted strongly affected how densely the tissue was innervated by serotonergic processes (Table 1). Reproductive tissue transplanted in mid- to late day 9 embryos was most likely to be heavily innervated. When transplants were performed $24 \mathrm{hr}$ later, the ectopic reproductive tissue was never
Table 2. Innervation density of ectopic male reproductive tissue as a function of normalized distance from the nearest ganglion (see Materials and Methods)

\begin{tabular}{lll}
$\begin{array}{l}\text { Innervation } \\
\text { density }\end{array}$ & $n$ & $\begin{array}{l}\text { Mean normalized distance } \\
(+ \text { SEM })\end{array}$ \\
\hline Heavy & 11 & $0.20 \pm 0.03$ \\
Moderate & 16 & $0.24+0.03$ \\
Light/none & 12 & $0.33 \pm 0.03$
\end{tabular}

The embryos were dissected 3-6 d after transplantation and stained with 5-HT antiserum and an HRP-conjugated $2^{\circ}$ antibody.

heavily innervated, although it was sometimes moderately innervated. Tissue transplanted in embryos between these ages received intermediate levels of serotonergic innervation. The period between mid-day 9 and early day 10 corresponds to the time during which the peripheral processes of $\mathrm{Rz}(5,6)$ first leave the ganglion (mid-day 9) and first contact the reproductive tissue (early 10) (Jellies et al., 1987).

Heavily innervated reproductive tissue often appeared to be nearer to the ganglion than uninnervated reproductive tissue. To confirm this observation quantitatively, we measured the distance between the ectopic reproductive tissue and the ganglion. In order to compare embryos from different ages, we normalized the distance between the nearest ganglion and the ectopic gonopore to segment length (see Material and Methods). The mean normalized distances from ganglion to ectopic gonopore differed significantly ( $p<0.05,1$-factor ANOVA) among pores that were heavily, moderately, or lightly innervated (Table 2). Pairwise comparisons showed that both moderately and heavily innervated gonopores were significantly closer to the ganglion than lightly innervated gonopores ( $p<0.05, F$ test); there was no significant difference between those heavily and moderately innervated.

\section{Effect of reproductive tissue innervation on standard $R z$ cells}

In order to determinc what effect contact with reproductive tissue had on standard Rz cells, individual cells were labeled by injecting them with HRP. Such stained $\mathrm{Rz}$ cells showed that the serotonergic innervation of ectopic reproductive tissue revealed by immunohistochemistry (described above) could come entirely from $\mathrm{Rz}$ cells in the nearest ganglion. These standard $\mathrm{Rz}$ cells sometimes sent many robust branches into the region of the ecoptic gonopore, often by way of novel nerve branches from the anterior and posterior segmental nerves (Fig. 4). In embryos that received transplants at mid- to late day 9,5 of 9 cells innervated reproductive tissue heavily; none of 8 cells in embryos that received transplants at early to mid-day 10 innervated ectopic reproductive tissue heavily. Of the cells that heavily innervated reproductive tissue in which such a determination was possible, 3 of 4 had central axons that did not extend completely through the connective to the adjacent ganglion (e.g., Fig. 4). In embryos that received transplants from early to mid-day 10 , all of the connective axons of $\mathrm{Rz}$ cells extended to adjacent ganglia $(5 / 5)$. These results suggest that contact with reproductive tissue at early stages may cause retraction of interganglionic processes in standard $\mathrm{Rz}$ cells, but further experiments are needed to confirm this possibility.

Every standard $\mathrm{Rz}$ cell that contacted reproductive tissue, even those innervating it heavily, retained a substantial arbor in the body wall $(17 / 17)$. In anti-5-HT-stained preparations, 


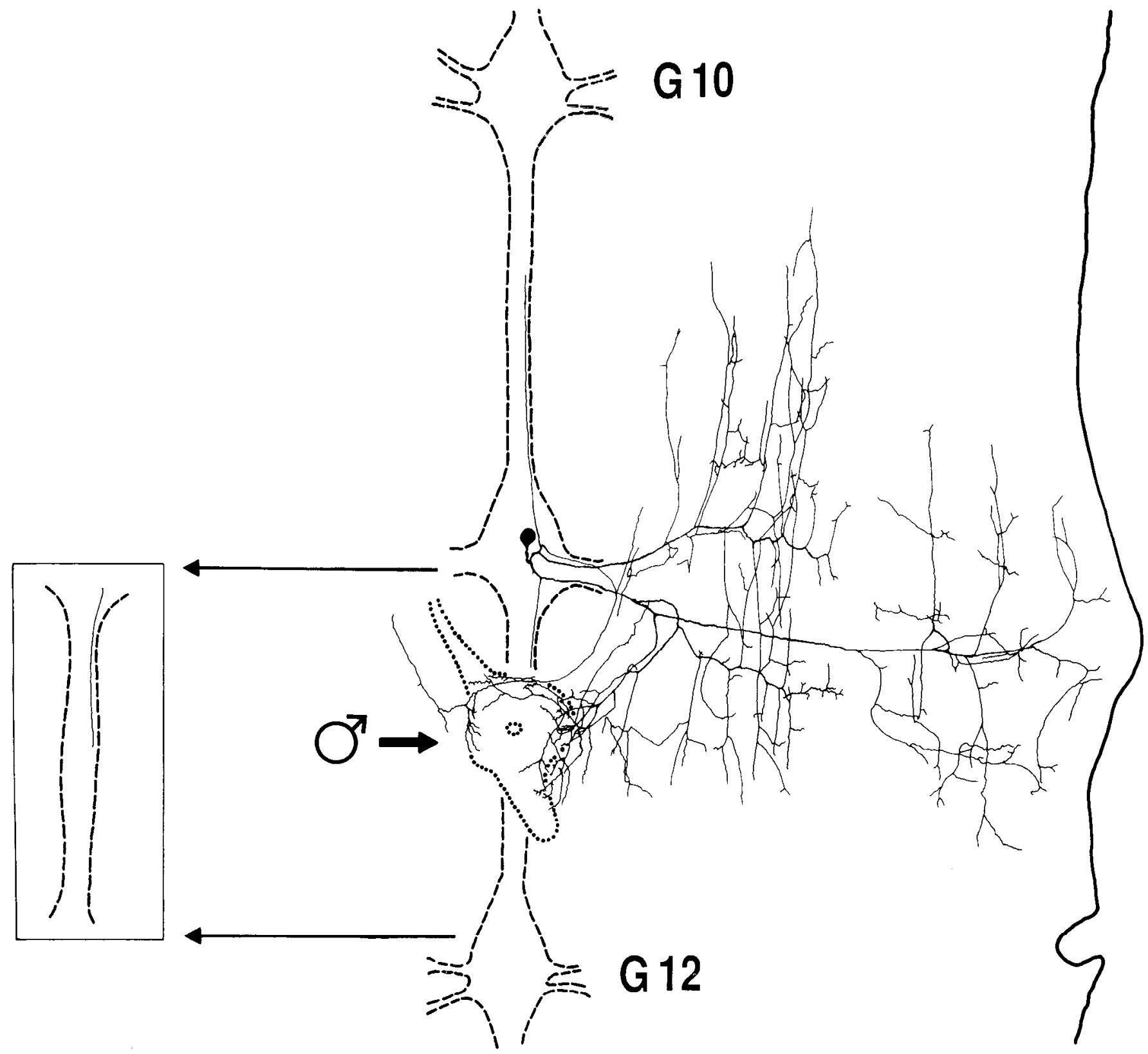

Figure 4. Innervation of ectopic male reproductive tissue by a standard $\mathrm{Rz}$ cell. This is a camera lucida drawing of an HRP-filled $\mathrm{Rz}$ (11) from a $16 \mathrm{~d}$ embryo into which reproductive tissue had been transplanted approximately $6 \mathrm{~d}$ earlier (at late day 9). In this preparation, a cut was made along the ventral midline to allow access to the ganglion for HRP injection. Dashed lines outline the ganglia and connectives; dotted outlines indicate the ectopic male reproductive tissue. One lateral duct extended posteriorly on the right side and ended abruptly; the other duct extended anteriorly on the left and continued beyond the drawing. The thick solid line at the right is the lateral edge of the germinal plate. The reproductive tissue pore lies ventral to the nerve cord. The connective and $\mathrm{Rz}$ axon between $\mathrm{G} 11$ and G12 is illustrated in the box (left) so as not to be confused with the innervation of the ectopic pore.

peripheral innervation in segments with heavily innervated reproductive tissue appeared, however, to proceed more slowly than in other nearby segments (Fig. 3). To measure the extent of peripheral serotonergic innervation in segments containing ectopic reproductive tissue, we stained serotonergic processes in embryos at various times after transplanting male reproductive tissue at mid- to late-day 9.

At 12-24 hr after transplantion, the nearby Rz cells grew out along their normal pathways into the periphery, and the transplanted tissue remained uninnervated. By $2 \mathrm{~d}$ after transplantion, the nearby $\mathrm{Rz}$ cell processes sent branches medially toward the site of ectopic tissue (Fig. 5). By $4 \mathrm{~d}$ after transplantion, the serotonergic innervation of ectopic male reproductive tissue was frequently quite heavy, including complex, heavy branches similar to the branches of $\mathrm{Rz}(5,6)$ to normal reproductive tissue (Fig. 6). At both 2 and $4 \mathrm{~d}$ after transplantation, extension of serotonergic processes in these segments was retarded compared with that in adjacent segments. Transplanted body wall that did not contain reproductive tissue was never heavily innervated, nor was the serotonergic innervation of the body wall retarded in such segments.

We measured the length of the longest serotonergic process 

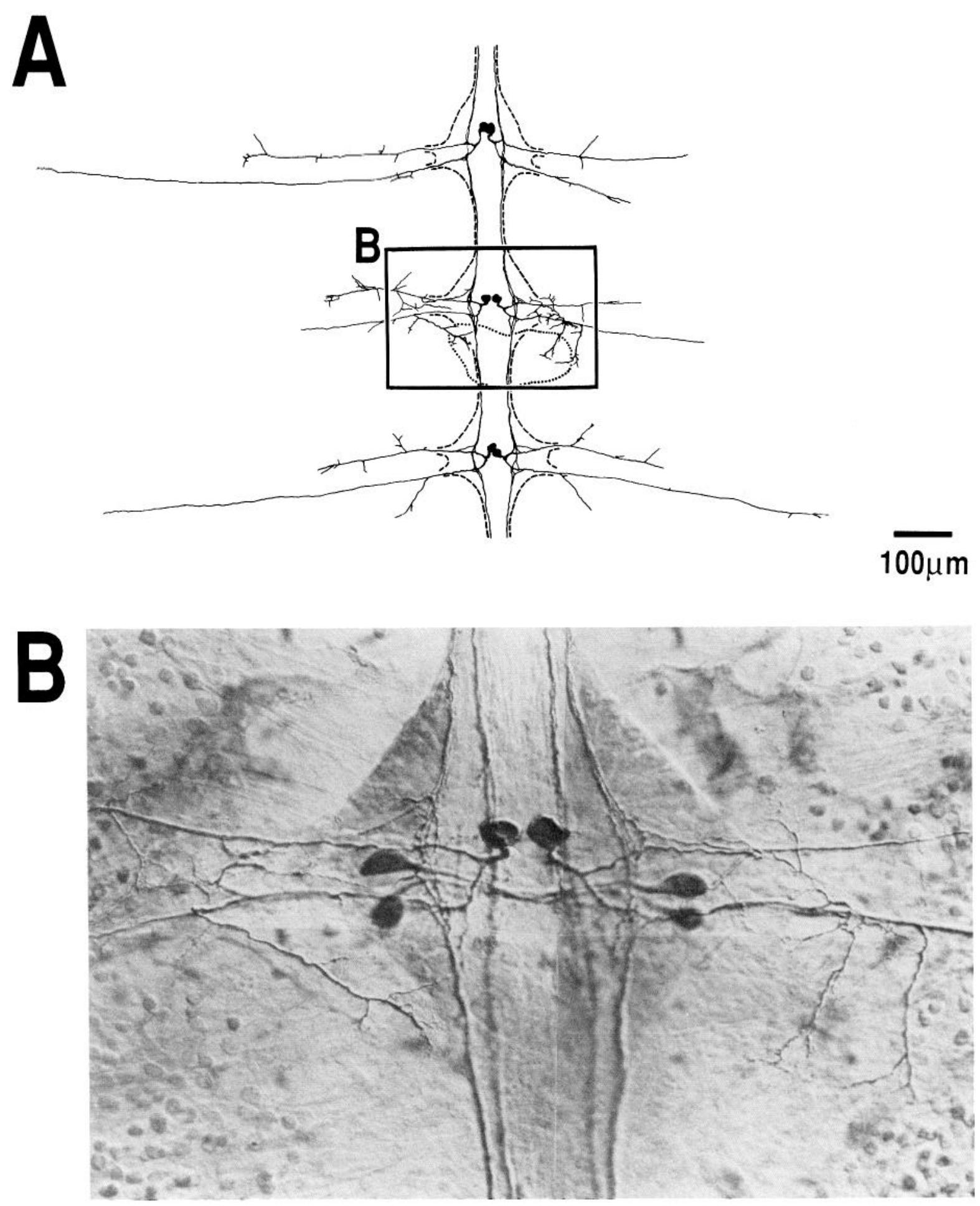

Figure 5. Serotonergic innervation of ectopic male reproductive tissue and nearby body wall $2 \mathrm{~d}$ after transplantion. A, Camera lucida drawing of segments 10-12 in a preparation stained with anti-5-HT. 5-HT-containing fibers and somata in the CNS are not drawn except for those belonging to $\mathrm{Rz}$ cells. Dashed lines indicate the edges of the ganglia and connectives; the dotted outline is the approximate region of ectopic reproductive tissue, which lies ventral to the nerve cord. $B$, Nomarski photomontage of the site of ectopic reproductive tissue innervation indicated by the box in $A$. Many complex branches extend into the region of the transplanted reproductive tissue.

in each of the 3 major peripheral nerves (A, PP, DP) at 2 and $4 \mathrm{~d}$ after transplantion to quantify the retardation of Rz process outgrowth. These measurements revealed that the 3 experimental treatments (see Materials and Methods) indeed differed significantly $(p<0.001,1$-factor ANOVA) in the length of their lateral processes in all 3 nerves at both 2 and $4 \mathrm{~d}$ after transplantation (Fig. 7). Processes in segments with ectopic reproductive tissue were always significantly shorter $(p<0.05$, 

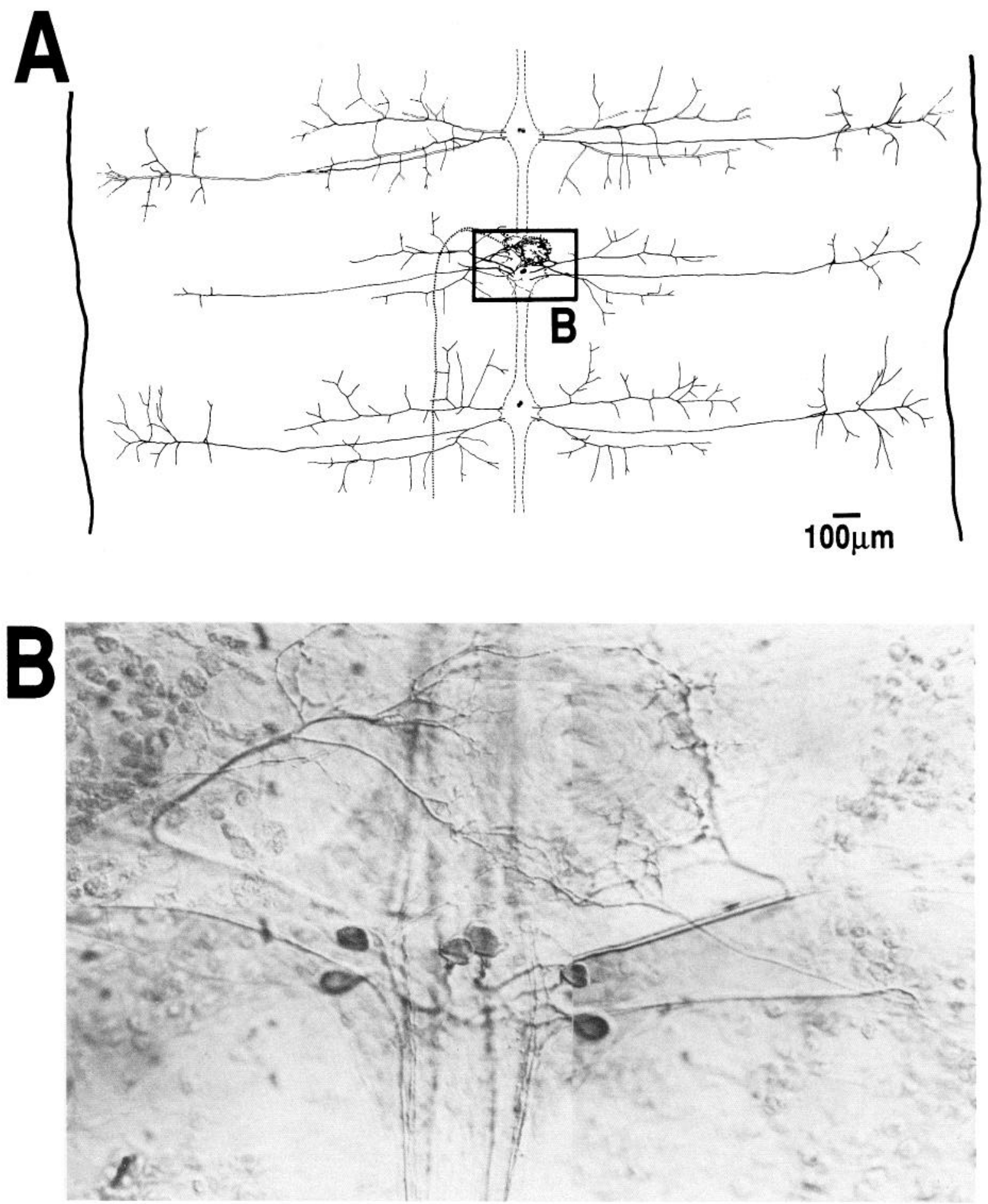

Figure 6. Serotonergic innervation of ectopic reproductive tissue and nearby body wall $4 \mathrm{~d}$ after transplantion. $A$, Camera lucida drawing of segments $10-12$ in a preparation stained with anti-5-HT. The dotted outline indicates the ectopic reproductive tissue, which lies ventral to the nerve cord. A single ectopic vas deferens on the left extends posteriorly; it runs medial and parallel to the host vas deferens (not drawn). Processes originating from the nerve roots, which appear to head medially into the ganglion, are actually ventral to the ganglion and heading toward the transplanted tissue. $B$, Nomarski photomontage of the site of ectopic reproductive tissue innervation indicated by the $b o x$ in $A$.

Scheffě's $F$ test) than either unoperated segments or segments with transplanted body wall.

This quantitative comparison could not be extended to $6 \mathrm{~d}$ after transplantion because laterally growing processes in most A and PP nerves had met medially growing processes from the dorsal territory and the DP nerves had reached essentially $100 \%$ of the body width. It was still apparent, however, that the density of innervation in the body wall of the segments containing ectopic reproductive tissue was lower than that of segments containing transplanted body wall and that of nearby unoperated segments (see Fig. 3).

One further observation seemed especially to suggest that 
2 days after Transplantation

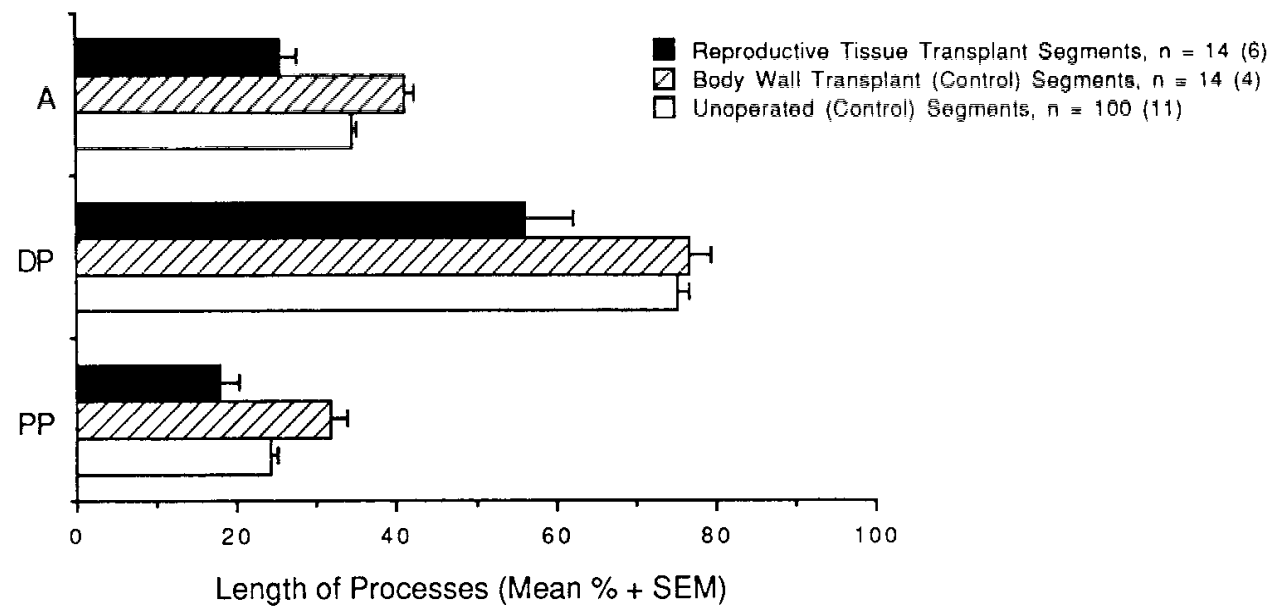

4 days after Transplantation

Figure 7. Extent of lateral growth of serotonergic processes in the $\mathrm{A}, \mathrm{PP}$, and DP nerves in segments containing reproductive tissue transplants, body wall (control) transplants, and unoperated (control) segments at 2 and $4 \mathrm{~d}$ after transplantation. Means (+SEM) are expressed as percentages of the distance from the ganglion to the edge of the germinal plate (see Materials and Methods). $n$ is the number of hemisegments measured; the values in parentheses are the numbers of embryos from which these are taken.

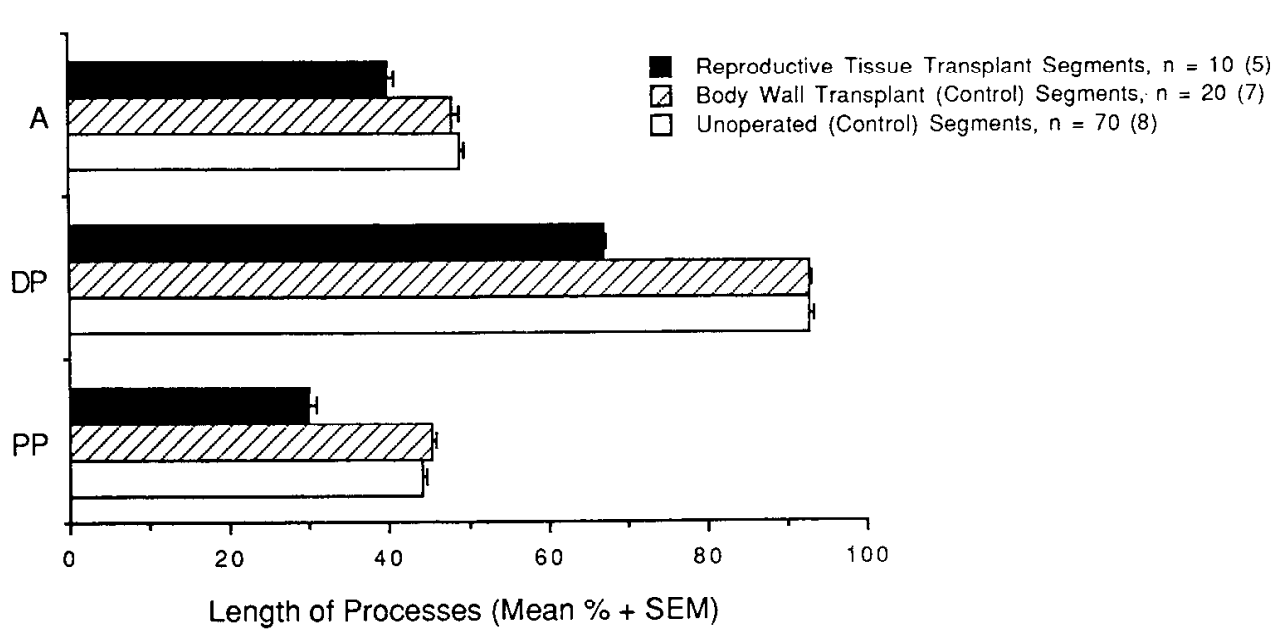

standard Rz cells might be "transformed" by target contact into reproductive $\mathrm{Rz}$ cells. Occasionally, the somata of $\mathrm{Rz}(5,6)$ in normal embryos stain much more darkly with the 5-HT antiserum than do those of standard $\mathrm{Rz}$ cells. In onc cxpcrimcntal embryo in which $\mathrm{Rz}(5,6)$ somata were stained darkly, somata of standard Rz. cells in the segment containing heavily innervated ectopic reproductive tissue were also darkly stained, whereas in all other segments, somata of standard $\mathrm{Rz}$ cells were lightly stained.

\section{Discussion}

In the preceding paper (Loer and Kristan, 1989a), we showed that competition could not explain the different target choices made by $\mathrm{Rz}(5,6)$ and standard $\mathrm{Rz}$ cells. At least 2 other mechanisms could be responsible for the respective target choices of homologous $\mathrm{Rz}$ cells: intrinsic differences in target preference or differences in the availability of targets and the timing of $\mathrm{Rz}$ cell interactions with potential targets. In this paper, we show that standard $\mathrm{Rz}$ cells act similarly to $\mathrm{Rz}(5,6)$ when given the opportunity to innervate reproductive tissue. Standard $\mathrm{Rz}$ cells show some, but not all, of the changes displayed by $\mathrm{Rz}(5,6)$ after they contact reproductive tissue. Furthermore, the timing of that contact appeared to be critical in determining some of the properties of these standard $\mathrm{R} z$ cells. Remaining differences between standard $\mathrm{Rz}$ cells that were exposed to reproductive tissue and $\mathrm{Rz}(5,6)$ may be due to intrinsic differences or to our inability to provide the standard $\mathrm{Rz}$ cells with all the external cues necessary for the complete transformation that is characteristic of $\mathrm{Rz}(5,6)$.

\section{Effects of timing and availability on target selection by standard $R z$ cells}

The density of innervation of transplanted male reproductive tissue depended on the time that the transplant was performed and on the nearness of transplanted tissue to a ganglion. These 2 factors may affect the same process. Ectopic reproductive tissue that is located close to the ganglion is probably contacted 
by $\mathrm{Rz}$ cell processes earlier than reproductive tissue that is farther away. Ectopic reproductive tissue located very near to a ganglion may be contacted by filopodia of $\mathrm{Rz}$ cell growth cones shortly after they exit the ganglion. This situation is similar to the interaction of $\mathrm{Rz}(5,6)$ with reproductive tissue occurring normally in segments 5 and 6 . Reproductive tissue that is transplanted far from the ganglion or $24 \mathrm{hr}$ later may mimic the conditions encountered by the branches of $\mathrm{Rz}(4,7)$ when they grow into the periphery of segments 5 and 6 . We have not tested, however, whether $\mathrm{Rz}(4,7)$ are the same as other standard $\mathrm{Rz}$ cells and are, thereby, able to innervate ectopic reproductive tissue heavily; it is possible that they are especially "resistant" to this target so that they may instead innervate the body wall of segments 5 and 6.

Because innervation of ectopic reproductive tissue is most successful when the tissue lies close to growing $\mathrm{Rz}$ cell processes, it is possible that this interaction is contact-mediated, perhaps by selective adhesion of filopodia. These results suggest that if reproductive tissue instead releases some attractive diffusible factor, it must act over only a short distance. Other observations of $\mathrm{Rz}$ cell processes growing to reproductive tissue are consistent with this idea (Jellies and Kristan, 1988).

Our results do not indicate how the propensity of Rz cells to innervate reproductive tissue is lost with time; the site of change could be either the $\mathrm{Rz}$ cell processes, the reproductive tissue, or both. $\mathrm{Rz}$ processes may lose a special affinity for reproductive tissue over time, and therefore be committed to a developmental pathway appropriate for standard $\mathrm{Rz}$ cells. A variation on this possibility is that only the first $\mathrm{Rz}$ cell processes to exit the ganglion have a high affinity for reproductive tissue. By midto late day $10, \mathrm{Rz}$ cell growth cones extend well beyond the edge of the ganglion and into the ventral body wall. Only later will fine branches from the main peripheral axons grow to the midline where they may contact ectopic reproductive tissue. The tips of these branches do not appear to have the same morphology as the initial Rz growth cones; thus, the first Rz growth cones sent into the periphery may have an affinity different from other growing $\mathrm{Rz}$ processes. A related possibility requires less specific interactions: $\mathrm{Rz}$ cells may be unable to provide a heavy innervation of reproductive tissue once they have committed a certain amount of their arbor to the body wall; there may be a limit to the arbor they can support (cf. Shepard and Murphey, 1986). Alternatively, reproductive tissue may no longer attract $\mathrm{Rz}$ cell processes by mid- to late day 10 . Such stage-specific effects of target tissues have been demonstrated in vitro (Pollack and Mulach, 1981; Nurcombe and Bennett, 1983; Heaton and Paiva, 1986).

\section{Transplanted male vs female reproductive tissue}

It is unclear at present why transplanted male reproductive tissue was more successfully innervated by standard $\mathrm{Rz}$ cell processes than was female reproductive tissue. There are a number of apparent differences between the male and female reproductive tissue. Male reproductive tissue is larger than female reproductive tissue, so it may provide a physically larger target. Male reproductive tissue is normally innervated both by $\mathrm{Rz}(5)$ and $\mathrm{Kz}(6)$, whereas female reproductive tissue is innervated only by $\mathrm{Rz}(6)$. Thus, more pathways leading to male reproductive tissue may be present and survive transplantation. Transplanted male reproductive tissue can be contacted by processes of penile motorneurons originating several segments away when this target is removed from its normal location (Baptista and Macagno, 1987). Neurons that arise postembryonically in ganglia 5 and 6 do not appear when male reproductive tissue, but not female reproductive tissue, is removed prior to their appearance (Baptista and Macagno, 1988a,b). Although these observations do not explain the differences found in the capacity of male reproductive tissue to acquire standard $\mathrm{Rz}$ cell processes, they do serve to illustrate considerable differences between the 2 tissues and suggest qualities of male reproductive tissue lacking or reduced in the female reproductive tissue.

\section{Effects of reproductive tissue innervation on standard $R z$ cells}

Contact with reproductive tissue can alter the morphology of standard $\mathrm{Rz}$ cells in ways similar to that of $\mathrm{Rz}(5,6)$. Standard $\mathrm{Rz}$ cells that heavily innervate ectopic reproductive tissue form thick processes with many branches. Such large, complex neurites are never seen normally arising from standard $\mathrm{Rz}$ cells. These processes enter ectopic reproductive tissue through new nerves reminiscent of the sex nerves in segments 5 and 6 . It is possible that $\mathrm{Rz}$ cells pioneer these pathways to the ectopic reproductive tissue or that they follow other neurons that are also attracted to this tissue. It is also possible that pathways to the reproductive tissue were transplanted along with the reproductive tissue (see Jellies and Kristan, 1988). If this is the case, then standard Rz cells are also capable of following the segmentspecific cues associated with these pathways.

Contact with ectopic reproductive tissue causes retardation, if not cessation or retraction, of growth in other processes of standard $\mathrm{Rz}$ cells. Such contact may cause standard Rz cells to retract interganglionic axons. Similar effects of specific targets on the growth of different neurites belonging to a single identified neuron have been demonstrated in vitro (Schacher, 1985). The presence of ectopic reproductive tissue is clearly associated with a slowing of the serotonergic innervation of body wall. Intracellular staining of the standard Rz cells innervating this ectopic tissue indicated that their primary fields were retained even when they heavily innervated ectopic reproductive tissue, unlike $\mathrm{Rz}(5,6)$, which retract their meager primary fields once they innervate reproductive tissue. Hence, standard Rz cells seem limited in the degree to which they can become like reproductive $R z$ cells. The cells may, of course, be limited by our experimental technique rather than by intrinsic differences between them and $\mathrm{Rz}(5,6)$.

Although it may be possible that transplantation of reproductive primordia earlier than mid- to late day 9 might have been more successful, this seems unlikely. At the earliest times that transplants were made, $\mathrm{Rz}$ cell processes did not yet extend beyond the ganglion. Thus, Rz cells could not have contacted reproductive tissue even if it were transplanted earlier. Previous experiments (Loer et al., 1987) strongly suggest that contact is necessary for the target to influence the development of the $\mathrm{Rz}$ cells. It seems more likely that contact with ectopic reproductive tissue is limited by the damage caused in transplantation. Thus, conditions for interaction between $\mathrm{Rz}$ cells and ectopic reproductive tissue are simply not optimal and limit the ability of standard $\mathrm{Rz}$ cells to follow a "reproductive" developmental pathway.

\section{Conclusions}

The results reported here and in the previous paper (Loer and Kristan, 1989a) show that segmentally appropriate target choice by $\mathrm{Rz}$ cells is not influenced by competition between $\mathrm{Rz}$ cells for specific targets, but that the availability of targets at an 
appropriate time and location is important to that choice. Although target contact is critical in this choice, intrinsic preferences for one target over another may also be important. $\mathrm{Rz}(5$, 6) innervate body wall slowly and only in the absence of their normal target. Standard Rz cells, although they show a strong propensity to innervate reproductive tissue, continue to innervate body wall in the presence of the alternate target.

Following normal target choice, standard $\mathrm{Rz}$ cells and $\mathrm{Rz}(5$, 6) follow different developmental pathways, each acquiring a distinctive morphology and synaptic connectivity (Glover, 1984; Glover and Mason, 1986; Jellies et al., 1987; G. Wittenberg, S. Adamo, C. Loer, and W. Kristan, unpublished observations). In the absence of their normal target, $\mathrm{Rz}(5,6)$ go on to develop like standard $\mathrm{Rz}$ cells by innervating body wall, extending axons to adjacent segments, elaborating a denser central neuropil (Loer et al., 1987; Loer and Kristan, 1989a), and acquiring certain excitatory synaptic connections (Loer and Kristan, 1989b). Following appropriately timed contact with ectopic reproductive tissue, standard $\mathrm{Rz}$ cells develop similarly to $\mathrm{Rz}(5,6)$. Although there are indications that intrinsic differences between homologous $\mathrm{Rz}$ cells act in this process as well, these results demonstrate that the development of segmentally appropriate morphology and synaptic connectivity of $\mathrm{Rz}$ cells is dependent upon interactions with specific target tissues.

\section{References}

Baptista, C. A., and E. R. Macagno (1988a) Modulation of the pattern of axonal projections of a lccch motor ncuron by ablation or transplantation of its target. Neuron (in press).

Baptista, C. A., and E. R. Macagno (1988b) The role of the sexual organs in the generation of postembryonic neurons in the leech Hirudo medicinalis. J. Neurobiol. 19: 707-726.

Dunn, O. J. (1964) Multiple contrasts using rank sums. Technometrics 6: $241-252$.

Fernandez, J., and G. Stent (1982) Embryonic development of the hirudinid leech Hirudo medicinalis: Structure, development and segmentation of the germinal plate. J. Embryol. Exp. Morphol. 72: $71-$ 96.

Glover, J. C. (1984) Structure, function, and development of serotonin-containing neurons in the leech. Doctoral dissertation, University of California, Berkeley.

Glover, J. C., and A. Mason (1986) Morphogenesis of an identificd leech neuron: segmental specification of axonal outgrowth. Dev. Biol. 115: 256-260.
Heaton, M. B., and M. Paiva (1986) The influence of target tissue age on neurite outgrowth from chick embryo trigeminal motor nucleus explants. Dev. Biol. 116: 314-318.

Humason, G. L. (1979) Animal Tissue Techniques, 4th ed., Freeman, San Francisco.

Kruskal, W. H., and W. A. Wallis (1952) Use of ranks in one-criterion variance analysis. J. Am. Stat. Assoc. 47: 583-621.

Jellies, J., and W. B. Kristan, Jr. (1988) An identified cell is required for the formation of a major nerve during embryogenesis in the leech. J. Neurobiol. 19: 153-165.

Jellies, J., C. M. Loer, and W. B. Kristan, Jr. (1987) Morphological changes in leech Retzius neurons after contact during embryogenesis. J. Neurosci. 7: 2618-2629.

Loer, C. M. (1988) Target specification of morphology and synaptic connectivity of identified neurons during embryogenesis of the leech. Doctoral dissertation, University of California, San Diego.

Loer, C. M., and W. B. Kristan, Jr. (1987) Peripheral target choices by identified neurons during embryogenesis of the leech. Soc. Neurosci. Abstr. 13: 594.

Loer, C. M., and W. B. Kristan, Jr. (1989a) Peripheral target choice by homologous neurons during embryogenesis of the medicinal leech. I. Segment-specific preferences of Retzius cells. J. Neurosci. 9: 513527.

Loer, C. M., and W. B. Kristan, Jr. (1989b) Central synaptic inputs to identified leech neurons are determined by peripheral targets. Science (in press).

Loer, C. M., J. Jellies, and W. B. Kristan, Jr. (1985) The possible role of target interactions in the development of segment-specific differences of an identified neuron. Soc. Neurosci. Abstr. 11: 957.

Loer, C. M., J. Jellies, and W. B. Kristan, Jr. (1987) Segment-specific morphogenesis of leech Retzius neurons requires particular peripheral targets. J. Neurosci. 7: 2630-2638.

Nurcombe, V., and M. R. Bennett (1983) The growth of neurites from explants of brachial spinal cord exposed to different components of wing bud mesenchyme. J. Comp. Neurol. 219: 133-142.

Pollack, E. D., and W. L. Mulach (1981) Stage dependency in eliciting target-dependent enhanced neurite outgrowth from spinal cord explants in vitro. Dev. Biol. 86: 259-263.

Schacher, S. (1985) Differential synapse formation and neurite outgrowth at two branches of the metacerebral cell of Aplysia in dissociated cell culture. J. Neurosci. 5: 1940-1948.

Shepard, D., and R. K. Murphey (1986) Competition regulates the efficacy of an identified synapse in crickets. J. Neurosci. 6: 31523160.

Sokal, R. R., and F. J. Rohlf (1981) Biometry, 2nd ed., W. H. Freeman, New York.

Zar, J. H. (1984) Biostatistical Analysis, 2nd ed., Prentice-Hall, Englewood Cliffs, NJ.

Zipser, B. (1979) Identifiable neurons controlling penile eversion in the leech. J. Neurophysiol. 42: 455-464. 